\title{
Resenha
}

TUNSTALL, Tricia. Changing Lives: Gustavo Dudamel, El Sistema, and the Transformative Power of Music. Nova York, ww Norton \& Company, 2012, 298 pp.

\section{El Sistema e suas aquisições no campo musical e social, segundo Tunstall}

\author{
Marcos Câmara de Castro \\ Universidade de São Paulo, Ribeirão Preto, SP, Brasil \\ mcamara@usp.br
}

Nós nunca tínhamos visto uma orquestra jovem que não fosse composta por tipos europeus, loiros e de olhos azuis

(Álvaro Rodas)

A autora chama de "Dudamania" a educação musical que pode ser um meio tanto para a capacitação individual quanto para a transformação social:

Mesmo seguindo uma importante carreira internacional como regente, ele (Dudamel) continua a reger a Orquestra Jovem Simón Bolívar da Venezuela regularmente, e é um incansável embaixador da visão de El Sistema, de melhorar a vida das crianças e dos jovens através do treinamento musical e da comunidade orquestral $(: x)$.

Como diz o mentor de todo esse "milagre", fundado há 37 anos, José Antonio Abreu, "minha luta é por uma sociedade na qual a arte não seja apenas uma dimensão estética da vida. Ela é um instrumento fundamental para o desenvolvimento de indivíduos e sociedades" (: xi). Num trabalho musical que não vê contradição entre acesso e excelência, Abreu parte do princípio de que "a pobreza não é só a falta de teto ou pão. É também uma ausência espiritual - solidão e falta de reconhecimento. O círculo vicioso da pobreza pode 
ser quebrado quando uma criança pobre materialmente adquire uma riqueza espiritual através da música”" (: xi-xii).

A autora conta que a escola básica (elementary school) nos EUA gasta uma média de 46 horas por ano em aulas de educação artística - "de longe o menor número entre os países desenvolvidos, e um contraste dramático diante do Japão e da Finlândia, onde a média é de 300 horas ou mais. E a desigualdade baseada em raça e classe com relação ao acesso à educação musical parece cada vez mais teimosamente entrincheirada" (: xiii). Levada à Venezuela por Jamie Bernstein (filha de Leonard), e por suas inquietaçóes particulares em direção a uma experiência musical que brotasse do esforço coletivo, contra a limitação inerente às aulas particulares (: xv), aqui é bom lembrar do que diz Ansermet, no Avant-propos do livro de Pierre Kaelin, L'Art choral, de $1974^{1}$, sobre "um dos maiores perigos da vida musical contemporânea" que é as pessoas crerem cultivar a música quando na verdade se limitam a ouvi-la. Este livro surgiu, segundo a autora, como

a crônica de [suas] exploraçóes e tentativas de entender a quase mágica capacidade de El Sistema de inspirar artistas, educadores e ativistas sociais por toda parte. E traça [sua] compreensão de que o ideal orientador da orquestra como escola para a comunidade civil é forte o suficiente para transcender efetivamente a distinção entre educação musical e transformação social (: xvi).

O rápido e crescente movimento internacional de replicar esse modelo é um dos desenvolvimentos sociais e artísticos mais importantes do século XXI. Uma vasta rede de orquestras para jovens em situação de risco: eis uma ideia sem precedentes e heterodoxa; "uma visão educacional que traz [às crianças] não só formação e competência, mas também comunidade, arte, disciplina e esperança" (: xvi-xvii). Ao contar uma das três maiores experiências de Debora Borda (presidente da Los Angeles Philarmonic), comparável ao concerto do sesquicentenário da New York Philarmonic, que começou com a orquestra tocando a abertura de Candide com o pódio vazio, em homenagem a Leonard Bernstein; ou na abertura do Walt Disney Concert Hall em Los Angeles, em 2002; o concerto de estreia de Dudamel também em Los Angeles, "Bienvenido, Gustavo", em 3 de outubro de 2009, "foi realmente um evento épico" e Tunstall conta que "a transmissão ao vivo pela Web foi assistida em 90 países pelo mundo, em todos os sete continentes” (: 17). 
"Um público eminentemente de fala espanhola veio com o desejo expresso do novo maestro, um venezuelano de 28 anos de idade [...], que insistiu para que seu concerto de abertura fosse gratuito e, pelo menos, metade da audiência fosse de latinos” (: 2).

A festa que aguardava a chegada de Dudamel em Los Angeles foi tamanha que, quando os ingressos ficaram disponíveis dois meses antes, na tarde de $1^{\circ}$ de agosto, esgotaram em menos de 90 minutos - o mais rápido sellout [ingressos esgotados] da história dos 18 mil lugares do Hollywood Bowl (: 3).

Dudamel diz que em El Sistema tudo está conectado e que os aspectos musicais e sociais do fazer musical nunca estão separados:

Tocar música junto está conectado com ser um melhor cidadão, com se preocupar com o outro, com trabalhar junto. A orquestra, você sabe, é uma comunidade. É um pequeno mundo, onde você pode criar harmonia. E, de fato, quanto você tem isso, conectado com a sensibilidade artística [...] qualquer coisa é possível. Tudo é possível (: 24).

Rafael Elster (diretor do Núcleo Sarria) diz: "Somos um programa de não-exclusão [...]. Toda criança que quer entrar entra. E tantos querem entrar que precisamos ter várias orquestras de vários níveis para acomodar todos" (: 33). E completa: "A música clássica por centenas de anos tem excluído gente. Estamos mudando isso. Somos o oposto disso! Dizemos a todo mundo, 'você pode tocar música clássica!” (: 34).

A fundação governamental que toca El Sistema ficou conhecida durante uma década como Fesnojiv $^{2}$ - Fundación del Estado para el Sistema Nacional de las Orquestras Juveniles e Infantiles de Venezuela -, mas o nome foi mudado recentemente para Fundación Musical Simón Bolivar (: 35). Rodrigo Guerrero (Diretor para o desenvolvimento institucional e negócios internacionais) diz que

num tempo e lugar em que as orquestras clássicas eram por definição das classes superiores e europeias [...], Abreu teve a inconcebível ideia de começar uma orquestra jovem composta inteiramente por venezuelanos [...]. Nesses 35 anos, o sistema cresceu como uma vasta rede de núcleos de orquestras jovens espalhadas por todo o país; há agora [2012] perto de 300 núcleos, [...] e cada núcleo abriga várias orquestras. Num país de apenas 28 milhôes de habitantes, aproximadamente 370 mil crianças e jovens participam atualmente de El Sistema; [...] toda criança, começando desde muito cedo, ganha um instrumento, aulas, e um lugar numa orquestra; as 
orquestras mais jovens tocam versóes simplificadas de obras do repertório, e essas obras são revisitadas em níveis cada vez mais adiantados - o que resulta que a quinta de Beethoven ou a Abertura 1812 de Tchaikovsky tornaram-se tão conhecidas pelas crianças e famílias venezuelanas quanto o atual reggaeton do rádio. [...] O número de crianças de El Sistema que vivem na pobreza é estimado entre $70 \%$ e $90 \%$. Para todas as crianças o programa é completamente gratuito, fornecendo instrumentos, professores, uniformes, e frequentemente também serviço social e alimentação (: 35-36).

Segundo Patrícia González, representante do Diretor Executivo Eduardo Méndez, o orçamento total da Fesnojiv para 2010 era de aproximadamente US\$ 120 milhôes. A maior parte dessa soma vem do governo federal; outras fontes incluem doaçóes particulares e transaçóes financeiras. Um relatório preparado pelo Banco Interamericano de Desenvolvimento, que apoia a Fesnojiv com uma soma substancial, cita a evidência de que os participantes de El Sistema têm melhor desempenho escolar e menos problemas de disciplina que os outros jovens que não participam. O índice de abandono escolar entre os adolescentes é de 26\%, mas para os participantes de El Sistema, o índice cai para 6,9\%. "Muitos dos mais bem formados por El Sistema acabaram tendo uma proeminente carreira internacional na música clássica” (: 36-37).

O cineasta Alberto Arvedo dirigiu Tocar y luchar (2006) e Let the Children Play (2009). O filme El Sistema: Music to Change Life, dirigido por Paul Smaczny e Maria Stodtmeier (2009) "eletrificou o circuito de festivais de cinema e ganhou prêmios de Chicago e Orlando a Grécia e Suíça”. Há ainda The Promise of Music, dirigido por Enrique Sanchez Lansch (2008). O programa de notícias da CBS, 60 Minutes, entrevistou Dudamel em 2008 e novamente em 2010; na primavera de 2010-11, ele foi convidado no programa de Tavis Smiley e Jay Leno. Artigos em jornais e revistas, e blogueiros que vão da música a lideranças corporativas, expuseram a atrasada descoberta pelos EUA de que a Venezuela está "explodindo em orquestras":

Ao longo dos minguados anos do século XX, especialistas ocuparam-se em lamentar o declínio da audiência para concertos orquestrais e em predizer a morte da música clássica ${ }^{3}$ nas mãos da cultura pop ocidental, tão agressiva que nenhuma tradição musical no mundo poderia resistir. Agora, subitamente, a mídia está repleta de imagens de hábeis e espirituosas crianças num canto pouco conhecido de um continente [...], tocando música clássica como se suas vidas dependessem disso. Mais digno de nota ainda, fica claro que de fato suas vidas, em muitos casos, dependem mesmo 
disso. Tão excitantes são as notícias da Venezuela que começou uma espécie de peregrinaçáo internacional de músicos, professores, formuladores de políticas e oficiais governamentais de todo o mundo, vindo para ver com seus próprios olhos (: 37-39).

Decorrência natural, a luteria foi criada como "um centro para fabricação de instrumentos e reparos", cuja intençáa é estabelecer oficinas de instrumentos por toda a Venezuela, "[n]uma vasta rede de luteristas paralela à rede de orquestras para suprir suas necessidades instrumentais - e composta, é claro, por graduados em El Sistema que aprenderam as técnicas da fabricação de instrumentos", já que, para Abreu: “cultura para o pobre não deve ser jamais uma cultura pobre" (: 39-40). Foi construído o Centro de Acción Social por la Música, que é o coração de El Sistema em Caracas, criado pelo arquiteto venezuelano Tomás Lugo (: 41). "Os estudantes do Sistema, não importando o quão pobres são os bairros de onde eles vêm, merecem o mais alto nível artístico e tecnológico" e seus dirigentes dizem: "[...] convidaremos os melhores professores no mundo para virem aqui, de maneira que ninguém precisará ir ao estrangeiro para estudar" (: 43-44). Jamie Bernstein disse que ela e sua família veem El Sistema como a realização do sonho de seu pai de educar os jovens no amor pela música clássica. Na hora do almoço, cortesia de El Sistema, servido com louças de prata para "não apenas tocar grande música numa sala de concertos espetacular, mas comer juntos e bem" (: 47-48). Num momento em que se vê no Brasil tantas publicaçóes e discussóes sobre a volta do ensino musical nas escolas públicas, o princípio básico de El Sistema, a "alegria de tocar junto como uma comunidade", tem a “performance como uma parte integral e contínua do processo de aprendizagem” (: 54).

Abreu, aos dezoito anos, foi estudar piano, órgão, cravo e composição com Vicente Emilio Sojo (fundador do modernismo musical venezuelano, "como um Villa-Lobos venezuelano"), no Conservatório Nacional de Caracas. Ao mesmo tempo, começou a estudar economia na Universidade Católica Andrés Bello, uma instituição jesuíta. Aos 25 anos, em 1964, obteve o PhD em economia do petróleo na universidade e graduação em composição e órgão do conservatório. Seu desempenho musical foi reconhecido com o Prêmio Nacional de Música Sinfônica em 1967. Durante o mesmo período ampliou suas credenciais acadêmicas com uma pós-graduação em economia na Universidade do Michigan (EUA). No início dos anos 1970, Abreu estava esculpindo uma expressiva carreira na academia e na arena política. Assumiu cadeiras em economia e planejamento em várias 
universidades, e serviu no congresso venezuelano como um de seus mais jovens deputados. Enquanto continuava uma ativa vida musical, tocando órgão em igrejas e piano em grupos informais com amigos, seu destino profissional parecia pertencer à economia e à política. Mas Abreu nunca esqueceu o contraste entre a alegria comunitária de sua educação inicial e a árdua, frequentemente solitária, experiência de estudo no conservatório. Nunca deixou de se incomodar com a quase impossibilidade, para jovens músicos venezuelanos, de encontrar emprego em orquestra ou oportunidades de tocar junto ${ }^{4}$ (: 56-57).

"Encontrei uma garagem abandonada em Caracas, não muito grande, mas suficiente para um ensaio de orquestra. E consegui doação para as estantes". Esta é a fundação mítica de El Sistema: “11 jovens numa garagem em 1975”. A primeira orquestra jovem de um país em que músicos de orquestra eram todos por definição estrangeiros. Nesta nova e pioneira orquestra, os mais adiantados ensinavam os mais iniciantes (: 59-60). Situação semelhante ocorreu em São Paulo, quando Olivier Toni foi ter com o então prefeito Faria-Lima, em 1969, não para pedir um emprego público, mas para fundar a Escola Municipal de Música, que seria atrelada à Orquestra Sinfônica Jovem Municipal, tendo assim os três pilares fundamentais de qualquer prática musical: poiésis, práxis e theoria. Não há testes: "se você quer tocar, é bem vindo"; “a participação na orquestra implica em ensinar uns e aprender com outros" (: 65). Em 1976, a Orquestra Nacional Juvenil de Venezuela - primeira orquestra latino-americana a participar do International Festival of Youth Orchestras, em Aberdeen, Escócia - voltou acompanhada de um entusiasmado Carlos Chávez para reger na Venezuela várias obras do repertório, além de sua Toccata for Percussion (: 67).

Com o presidente Carlos Andrés Pérez ${ }^{5}$ a orquestra jovem de Abreu torna-se um projeto com verba estatal, um programa de desenvolvimento da juventude através da música. Abreu diz: "Como em toda a América Latina, os ministros da cultura compartilham de uma ideia de arte muito elitista, como algo para uma minoria privilegiada, eis porque, desde o começo, eu quis o reconhecimento oficial do Estado de que se tratava de um programa social" (: 69):

Durante muitos anos, mesmo enquanto eu estava desenvolvendo a orquestra jovem nacional, viajei pela Venezuela [...]. Procurava qualquer lugar onde um núcleo poderia começar. Às vezes encontrava uma casa velha para ensaiar. Às vezes um regente de banda que poderia ensinar. Ou um 
professor aposentado que tivesse talento para ajudar as crianças a tocar. Qualquer coisa podia ser a semente de um núcleo que poderia nascer (: 72).

Com o tempo e o sucesso do projeto, vieram, além do financiamento público, as contribuiçôes privadas e os auxílios municipal e provincial, além do federal. Quanto às questôes sobre acesso e excelência,

Um dos grandes e perenes debates no campo da arte-educação sempre foi em torno de acesso versus excelência - se é mais importante estender a educaçáo artística o mais amplamente possível ou adquirir um alto nível artístico entre uma pequena elite. Abreu, parece, nunca assinou embaixo dessa dicotomia. Desde os primeiros anos de El Sistema, a visão do Maestro abarcou tanto o acesso ilimitado quanto um nível artístico superior, e vem perseguindo ambos os objetivos com igual zelo (: 76).

Ele conta à autora sobre um grupo de músicos estadunidenses que visitaram um núcleo provincial e ficaram surpresos com a alta qualidade dos instrumentos que até as menores crianças tocavam. "O que eles não entendem [...], diz Abreu, é que quanto mais pobre for a comunidade, mais você deve objetivar o mais alto nível de excelência artística”. Em 1980, foi criado o Conservatório Simón Bolívar, com aulas de instrumento, harmonia, solfejo e linguagem musical (: 76-77). Com o tempo, El Sistema também criou padróes de excelência para instrumentistas adiantados e desenvolveu princípios e práticas pedagógicos para infância. Susan Siman observa que:

nós não tínhamos um método específico [...]. Estávamos abertos para tudo - Susuki, Kodály, muitas coisas. Encorajávamos o desenvolvimento da coordenação motora fina fazendo réplicas dos instrumentos em papel mâché ou madeira em que as crianças podiam aprender a 'tocar' antes de ter a capacidade de tocar instrumentos reais. $\mathrm{E}$ isso também os ensinava como amar e cuidar de um instrumento" (: 78-79).

O dirigente da Fesnojiv, Frank Di Polo, diz que a qualidade superior do treino para as crianças mais jovens é um dos mais importantes e preciosos elementos do Sistema. "Desenvolver maneiras de ensinar música para crianças de um, dois ou três anos [...] é uma das mais altas realizaçôes. É grande parte do que vem a ser o Sistema" (: 79).

Nomeado em 1983 Ministro da Cultura, Abreu reformulou o tradicional modelo elitista dos ministérios da cultura latino-americanos numa imagem mais progressiva e 
orientada para a educação. Um de seus primeiros atos como ministro foi iniciar a criação de um instituto de música de nível universitário, assim jovens músicos com a ambição de seguir uma carreira profissional não precisariam ir para o exterior para sua Educação Superior (: 82). Apesar de ser um músico excepcional com múltiplos talentos, Abreu não se vê como regente, muito embora tenha estado à frente tanto da orquestra jovem quanto de outros grupos ${ }^{6}$. Seu objetivo maior sempre foi "promover a orquestra, e não regê-la". Convidou Eduardo Mata ${ }^{7}$ a assumir a Orquestra Jovem Simón Bolivar, e vem conseguindo sobreviver aos mais variados ventos políticos num espectro que vai da centro-direita à esquerda de Hugo Chávez, mantendo o Sistema separado de partidos políticos” (: 84). Desde a formalização da Fesnojiv, em 1996, apoios adicionais vieram de outras fontes, além do governo venezuelanao, Unicef, Companhia Telefônica Nacional da Venezuela e Banco Mundial. O Banco Interamericano de Desenvolvimento reconheceu o impacto social do programa com uma série de empréstimos substanciais. Sobre o empréstimo do BID de 150 milhões em 2007, um artigo no NYT do jornalista Arthur Lubow informou que “o levantamento de tal benefício comparado à diminuição da evasão escolar e o declínio da criminalidade, o banco calculou que cada dólar investido no Sistema colhe cerca de US\$ 1,68 em dividendos sociais". Como diz Rodrigo Guerrero, diretor para o desenvolvimento institucional e negócios internacionais, "trinta anos atrás, o Maestro e seus amigos iam por aí e diziam 'Quem quer tocar música?' Agora é o oposto: todo mundo pelo país vem e diz 'nós queremos tocar música”" (: 84-85).

O Sistema continua a expandir seus esforços no sentido de atingir as populaçóes marginalizadas e vários núcleos pioneiros passaram a priorizar o atendimento de crianças com deficiência, criando meios para que deficientes visuais e auditivos, e deficientes físicos participem em performances orquestrais e corais. Outra iniciativa estabeleceu núcleos nas prisóes, a partir de 2007, onde tocam música popular venezuelana e clássicos sinfônicos. Abreu tem também a ambição de unificar as bases pedagógicas de cada instrumento por todo o país, criando academias específicas, unificando tradiçóes através da promoção de festivais anuais. O conceito que norteia o Conservatório Simón Bolívar tem na prática coletiva a parte essencial do programa de ensino, e na área de Ensino Superior, foi consolidado o Instituto de Música, no âmbito da Universidade Nacional das Artes. Planos para o futuro incluem um incremento das atividades corais e de composição (: 86-88). Nos EUA, Abreu vem recebendo honrarias e prêmios em várias cidades e 
universidades, culminando com o TED Prize ${ }^{8}$, que levou seu trabalho e sua missão para um novo patamar de notoriedade internacional (: 93-94). A organização TED ${ }^{9}$ premia Ideias com Valor de Propagação (Ideas Worth Spreading), criando oportunidades para tornar sonhos realidade. Em seu discurso, Abreu preconizou a formação de um programa (fellowship) nos EUA que foi inaugurado no Conservatório New England, em Boston (: 94).

"Quando o Maestro estava regendo, aprendíamos mais que técnica orquestral. Era um processo de criar música e família ao mesmo tempo", diz Susan Siman, violinista e professora (: 110). Um dos aspectos mais surpreendentes da Orquestra Simón Bolívar é que seu admirado fundador e líder não permaneceu como seu regente principal. O resultado é uma orquestra sem disputas internas, sem invejas ou animosidades táo presentes nas orquestras consolidadas por todo o mundo ${ }^{10}$ (: 111-112). A competitividade é um elemento da condição humana, mas o modelo alternativo de El Sistema, de interdependência cooperativa, parece satisfazer tão profundamente que é muitas vezes capaz de superar tais sentimentos (: 119). Simon Rattle diz que "esta orquestra é claramente a coisa mais importante do mundo para esses jovens. E isso fica claro e eloquente na música que fazem"; Claudio Abbado diz que a El Sistema e suas orquestras são "o projeto musical mais importante no mundo de hoje”; e Plácido Domingo, depois de ouvi-los disse que não esperava "caminhar pelo paraíso e ouvir vozes celestiais" e que na verdade, nunca se sentiu tão emocionado por tanta qualidade. Em 1999, A Orquestra Jovem Simón Bolívar ganhou o Prêmio Internacional de Música da Unesco por ser "um exemplo para a juventude e para o mundo" (: 120-121).

Atualmente, quase metade dos integrantes da Simón Bolívar está envolvida em obter uma graduação universitária (: 124). Uma das orquestras de El Sistema, a Orquestra Teresa Carreño, fez sua primeira turnê internacional em 2010 e um comentarista de uma rádio de Berlim elogiou sua Quinta de Beethoven, dizendo que "esses jovens venezuelanos deram nova vida e abriram os ouvidos alemães para sua própria música” (: 126). Debora Borda anunciou em 2007 a nova parceria chamada YOLA, Youth Orchestra Los Angeles, inspirada pelo Sistema, com o objetivo de criar entre três e cinco orquestras em comunidades carentes de Los Angeles (: 141) - iniciativas que não deixam de nos remeter às tímidas manifestações no Brasil com relação a El Sistema. A perspectiva da parceria do New England Conservatory de Boston e Abreu é criar um movimento pan-americano, já que "Novo Mundo" são as três Américas e ele confirma que o que está sendo criado é "uma 
nova e transcontinental cultura musical e social”, em moldes totalmente diferentes do que até hoje a música europeia vem sendo praticada, com suas origens na aristocracia e na ópera $^{11}(: 143)$.

Enquanto no Brasil discute-se sobre o nível internacional da Osesp - que já chegou a consumir $1 / 3$ do orçamento da Secretaria de Cultura e pretende ser "top" no mundo - e a volta do ensino musical nas escolas públicas, o eixo Venezuela-Los Angeles-Boston preocupa-se em fazer crescer El Sistema nos EUA que, nas palavras de Mark Churchill"12 "é a mais nova e importante ideia em educação musical". Um dos principais articuladores da importação de El Sistema para o EUA (El Sistema USA), Eric Booth, diz que os princípios e práticas de El Sistema desafiam alguns pressupostos fundamentais da comunidade de arte-educação dos EUA: “aqui tendemos a pensar o 'profundo' e o 'amplo' como modos mutualmente exclusivos de abordar o aprendizado artístico. Em El Sistema eles coexistem. O aprendizado musical lá é ao mesmo tempo profundo e democrático. Nós não temos nada assim aqui" (: 148-149). O pressuposto de que todos têm o que ensinar e que conhecimento e habilidade musicais são para ser compartilhados está enraizado em El Sistema desde suas origens (: 163). O princípio de repertório compartilhado é uma forte tradição em El Sistema. Crianças em estágios mais iniciantes tocam versóes simplificadas das mesmas obras que tocarão mais tarde em suas versóes originais, formando assim um núcleo de repertório de todas as orquestras do sistema (: 167-168). Ensaios de, em média, quatro horas diárias são o foco que é suplementado com aulas individuais; a técnica sonora musical e a empatia comunitária são objetivos irmãos (: 170). O mais popular instrumento na Venezuela é o Cuatro, e há grupos espalhados pelo país, dentro do sistema. "Precisamos ter os melhores instrumentos para as crianças mais pobres; os melhores professores para as crianças mais pobres; as melhores instalaçóes para as crianças mais pobres” (: 172-173).

Os princípios básicos de El Sistema podem ser descritos como segue: 1) constância de princípios e flexibilidade de métodos; 2) o processo de interação humana através do aprendizado musical não é um meio para um fim, é o principal fim em si mesmo; 3) no ensaio ou na performance, fazer música é uma experiência tanto de atividade criativa quanto de um meio de se ter uma profunda satisfação em estar junto; 4) excelência artística é parte inseparável da construção da comunidade orquestral; 5) unidade entre os objetivos musicais e sociais (: 175). El Sistema constitui um desafio a alguns aspectos fundamentais de nossa sabedoria convencional a respeito de crianças, educação e arte. Entre esses 
fundamentos, está nossa tendência de relacionar intensidade com trabalho, e alegria com brincadeira - que em El Sistema estão combinados. "Nunca esquecemos da alegria", diz Dudamel (: 176). Alegria e intensidade combinadas fazem da performance uma extensão natural do ensaio. Quanto às discussóes sobre o ensino da música que tanto vêm sendo travadas no Brasil, em que os céticos acham que a ênfase na música clássica europeia pode acelerar o desaparecimento de uma forte tradição musical popular, o oposto tem acontecido na Venezuela e a música popular tradicional tem se tornado mais forte que nunca. Músicos do Sistema têm trabalhado sobre o idioma popular e novas e mais complexas versóes da música tradicional têm se desenvolvido, numa espécie de Música de Câmara típica venezuelana (: 183).

O núcleo de Barquisimeto (capital do estado de Lara) é conhecido por ser o lugar de Gustavo Dudamel, mas é também o que tem, entre suas 3000 crianças, 340 crianças com deficiência, incluindo surdez, deficiência visual, autismo e deficiência intelectual. Ali se transcrevem partituras para o Braille e crianças com deficiência visual tocam lado a lado com seus outros colegas na orquestra (: 188). "Nossa missão é quebrar as barreiras existentes para essas crianças em todo o mundo", diz sem qualquer traço de sentimentalismo Jhonny Gómez, diretor do programa piloto com crianças com deficiência (: 189), para quem "a alma não tem necessidades especiais. A alma é completa" (: 196). Muitos dos ex-alunos do Sistema acabam tendo outra profissão, mas continuam a ensinar nos núcleos em bases regulares (: 198). Em 2009, havia talvez 5 ou 6 programas nos EUA baseados no modelo de El Sistema. Em 2011, há pelo menos 50 programas e a lista cresce em semanas ou até mesmo em dias (: 239). Cada iniciativa tem seu perfil particular e trajetória, de acordo com suas próprias especificidades e contexto cultural. Os diretores do núcleo de San Diego tomaram a iniciativa de propor o nome de José Antonio Abreu ao Comitê do Prêmio Nobel da Paz. YOLA (Youth Orchestra Los Angeles) - um dos mais visíveis programas inspirados em El Sistema - há três anos vem perseguindo seu objetivo de deixar a polícia longe através da criação de comunidades orquestrais para as crianças (: 247), desafiando as gangues e propondo-lhes comunidades (: 255); transformando a maneira de se ver orquestras jovens apenas como excelência (: 259). Sem medo de cometer erros, a excelência vem de ensaios e erros (: 260).

A capa (jacket), terceirizada ${ }^{13}$, deste livro de Tricia Tunstall, é de mau gosto: pelo punho da camisa, vê-se que o corpo está de terno ou casaca, a mão direita segura uma 
batuta com a ponta dos dedos polegar, médio e indicador, enquanto que o mínimo está ligeiramente levantado, sugerindo delicadeza no gesto. A mão esquerda faz uma concha, como se estivesse recebendo as intenções da batuta ligeiramente inclinada para baixo. No canto esquerdo inferior, uma menina afrodescendente olha, maravilhada, para aquelas "sábias" mãos com olhar agradecido e entusiasmado. Acima à esquerda, três meninos tocam trombones como se estivessem no céu. O mau gosto da imagem nada tem a ver com o belo conteúdo do livro de Tunstall - escritora, musicista e educadora, que mantém um estúdio na região de Nova York, onde ensina piano, apreciação musical e história da música. Tunstall também é escritora, o que explica em grande parte seu desembaraço ao narrar sua experiência com El Sistema da Venezuela.

Lê-se num letreiro sob um retrato de Beethoven, na entrada de um dos núcleos: A única experiência de excelência que conheço é a bondade (: 28).

\section{Notas}

${ }^{1}$ Ed. Berger-Levrault, p.5, Boulogne-Billancourt.

2 Ver: http://www.fesnojiv.gob.ve/

${ }^{3}$ A esse respeito, na linha de frente está Norman Lebrecht.

${ }^{4} \mathrm{Na}$ página 57, Tunstall conta a dramática história de um fagotista que, nos anos 1970, pôs fogo no instrumento, como um ato de protesto à situação dos músicos venezuelanos.

${ }^{5}$ Que governou o país por duas vezes: de 1974 a 1979 e de 1989 a 1993.

$6 \mathrm{Na}$ página 110, David Ascanio conta sobre a capacidade única de Abreu de absorver e compreender a música: "Vi certa vez um jovem compositor trazer-lhe uma partitura orquestral inédita. O Maestro olhou a partitura durante uns poucos minutos e depois foi ao piano e tocou-a impecavelmente, fazendo comentários [...]. Ele pode tocar qualquer peça musical que ele veja, imediatamente".

${ }^{7}$ Eduardo Mata (México, 1942-1995), aluno de Carlos Chávez, regente da Sinfônica de Dallas por 17 anos, promotor dos compositores latino-americanos.

${ }^{8}$ Disponível em: http://www.ted.com/talks/jose_abreu_on_kids_transformed_by_music.html

${ }^{9}$ O Prêmio TED é atribuído anualmente a uma personalidade excepcional, que recebe US $\$ 100.000$. Ver: http://www.tedprize.org/ 
${ }^{10}$ Cf. Lehmann, Bernard. L’Orchestre dans tous ses éclats. Paris, La Découverte, 2005. Ver também minha resenha em português em: http://www.anppom.com.br/opus/data/issues/archive/15.1/files/ OPUS_15_1_full.pdf (acesso em 29/04/2012).

11 Cf. Ayer, Julia. 2005. "American Orchestras Create a European Tradition in Their Own Fashion". In More than Meets the Ear: How Symphony Musicians Made Labor History. Minneapolis, Syren Book Company, pp.3-20.

12 Em 2005, Churchill liderou a assinatura do "Contrato de Amizade" entre New England Conservatory e El Sistema.

13 Sobrecapa (jacket design) de Chika Azuma, Graphic Designers, New York. 